\title{
Letter commenting on "Ultrasound evaluation of inferior vena cava compression in tilted and supine term parturients"
}

\author{
Christina Massoth, MD (1) - Manuel Wenk, MD, PhD
}

Received: 20 July 2021/Revised: 30 July 2021/ Accepted: 30 July 2021/Published online: 22 September 2021

(C) The Author(s) 2021

Keywords supine hypotension · left lateral tilt . aortocaval compression syndrome .

inferior vena cava syndrome

To the Editor,

We thoroughly enjoyed reading the interesting article "Ultrasound evaluation of inferior vena cava compression in tilted and supine term parturients" by Gagné et al. who assessed the postural changes of the inferior vena cava collapsibility index (IVCCI) by point-of-care ultrasound in term pregnant women undergoing Cesarean delivery. ${ }^{1}$ They report that the IVCCI, previously described to increase with hypovolemia, is significantly higher in the supine position compared with the $15^{\circ}$ left lateral position at baseline, an effect that was no longer detectable after the induction of spinal anesthesia and infusion of phenylephrine.

These results are in line with recent findings from randomized controlled trials investigating the lack of efficacy of the $15^{\circ}$ left lateral tilt at reducing maternal hypotension or affecting fetal acid base status, ${ }^{2}$ further supporting the paradigm shift to finally abandon the

This letter is accompanied by a reply. Can J Anesth 2022; this issue.

C. Massoth, MD ( $\square)$

Department of Anesthesiology, Intensive Care and Pain

Medicine, University Hospital Münster, Münster, Germany

e-mail: christina.massoth@ukmuenster.de

M. Wenk, MD, PhD

Department of Anesthesiology and Intensive Care and Pain

Medicine, Florence - Nightingale - Hospital Düsseldorf,

Düsseldorf, Germany practice of lateral tilt in obstetric anesthesia. Nevertheless, the authors' conclusion of recommending inferior vena cava (IVC) examinations as a potentially useful tool in detecting patients more sensitive to position is debatable.

First, given the substantial alterations in the last trimester due to physiologic changes, the validity of IVCderived hemodynamic assessments based on IVC-derived parameters may be unreliable. The direct impact of the growing uterus regularly increases the central venous pressure to a level of $20-30 \mathrm{~mm} \mathrm{Hg}$ in the supine position at term. ${ }^{3}$ Second, our current conceptual understanding of IVC compression and supine hypotension in pregnancy has significantly evolved from recent magnetic resonance imaging findings, indicating a crucial role of the azygos system for circulatory maintenance during pregnancy. To compensate for the near occlusion in almost all women at term, the blood flow in the azygos vein increases by up to $220 \%$ in the supine position. ${ }^{4}$ Nevertheless, the capacity of this mechanism depends on the anatomical variability of the collateral system, thereby explaining why most pregnant women are asymptomatic in the supine position. However, a few who present with lesser increases in azygos blood flow may show the characteristic symptoms of IVC compression. ${ }^{5}$

In conclusion, methods of IVC assessment might become unreliable in women at term because of physiologic changes during pregnancy, a fact that might explain why Gagné and colleagues were unable to correlate pre-spinal supine IVCCI measurements to the vasopressor requirements during surgery.

Disclosures None.

Funding statement None. 
Editorial responsibility This submission was handled by Dr. Sheila Riazi, Associate Editor, Canadian Journal of Anesthesia/Journal canadien d'anesthésie.

Funding Open Access funding enabled and organized by Projekt DEAL.

Open Access This article is licensed under a Creative Commons Attribution-NonCommercial 4.0 International License, which permits any non-commercial use, sharing, adaptation, distribution and reproduction in any medium or format, as long as you give appropriate credit to the original author(s) and the source, provide a link to the Creative Commons licence, and indicate if changes were made. The images or other third party material in this article are included in the article's Creative Commons licence, unless indicated otherwise in a credit line to the material. If material is not included in the article's Creative Commons licence and your intended use is not permitted by statutory regulation or exceeds the permitted use, you will need to obtain permission directly from the copyright holder. To view a copy of this licence, visit http://creativecommons.org/licenses/ by-nc/4.0/.

\section{References}

1. Gagné MP, Richebé P, Loubert C, et al. Ultrasound evaluation of inferior vena cava compression in tilted and supine term parturients. Can J Anesth 2021; DOI: https://doi.org/10.1007/ s12630-021-02051-w.

2. Liu T, Zou S, Guo L, et al. Effect of different positions during surgical preparation with combined spinal-epidural anesthesia for elective cesarean delivery: a randomized controlled trial. Anesth Analg 2020, DOI: https://doi.org/10.1213/ane.0000000000005320.

3. Scott $D B$. Inferior vena caval occlusion in late pregnancy and its importance in anaesthesia. Br J Anaesth 1968; 40: 120-8.

4. Humphries A, Mirjalili SA, Tarr GP, Thompson JM, Stone P. The effect of supine positioning on maternal hemodynamics during late pregnancy. J Matern Neonatal Med 2019; 32: 3923-30.

5. Humphries A, Mirjalili SA, Tarr GP, Thompson JM, Stone P. Hemodynamic changes in women with symptoms of supine hypotensive syndrome. Acta Obstet Gynecol Scand 2020; 99: 631-6.

Publisher's Note Springer Nature remains neutral with regard to jurisdictional claims in published maps and institutional affiliations. 